\title{
ANAEROBIC TREATMENT OF GLYCEROL FOR METHANE AND HYDROGEN PRODUCTION
}

\author{
T. VLASSIS ${ }^{1,2}$ \\ G. ANTONOPOULOU 1,2 \\ K. STAMATELATOU ${ }^{3}$ \\ G. LYBERATOS ${ }^{2,4, *}$
}

\author{
${ }^{1}$ Department of Chemical Engineering, University of Patra, \\ Karatheodori 1 st., 26500 Patras, Greece \\ ${ }^{2}$ Institute of Chemical Engineering and High Temperature Chemical \\ Processes, 26504 Patras, Greece \\ ${ }^{3}$ Department of Environmental Engineering \\ Democritus University of Thrace, 67100 Xanthi, Greece \\ ${ }^{4}$ School of Chemical Engineering \\ National Technical University of Athens \\ 15780, Athens, Greece
}

Received: 05/12/11

Accepted: 09/03/12 *to whom all correspondence should be addressed: e-mail: lyberatos@chemeng.ntua.gr

\begin{abstract}
This work focused on glycerol exploitation for biogas and hydrogen production. Anaerobic digestion of pure glycerol was studied in a continuous stirred tank reactor (CSTR), operated under mesophilic conditions $\left(35^{\circ} \mathrm{C}\right)$ at various organic loading rates. The overall operation of the reactor showed that it could not withstand organic loading rates above $0.25 \mathrm{~g} \mathrm{COD}^{-1} \mathrm{~d}^{-1}$, where the maximum biogas $\left.\left(0.42 \pm 0.05 \mathrm{~L}_{(\mathrm{g} \mathrm{COD}}\right)^{-1}\right)$ and methane $\left.\left(0.30 \pm 0.04 \mathrm{~L}_{(\mathrm{g} \mathrm{COD}}\right)^{-1}\right)$ production were achieved. Fermentative hydrogen production was carried out in batch reactors under mesophilic conditions $\left(35^{\circ} \mathrm{C}\right)$, using heat-pretreated anaerobic microbial culture as inoculum. The effects of initial concentration of glycerol and initial $\mathrm{pH}$ value on hydrogen production were studied. The highest yield obtained was $22.14 \pm 0.46 \mathrm{~mL} \mathrm{H}_{2}\left(\mathrm{~g} \mathrm{COD}_{\text {added }}\right)^{-1}$ for an initial $\mathrm{pH}$ of 6.5 and an initial glycerol concentration of $8.3 \mathrm{~g} \mathrm{COD} \mathrm{L}^{-1}$. The main metabolic product was 1.3 propanediol (PDO), while butyric and acetic acids as well as ethanol, at lower concentrations, were also determined.
\end{abstract}

KEYWORDS: Glycerol, anaerobic digestion, methane, biogas, fermentative hydrogen production, biohydrogen, initial $\mathrm{pH}$, initial glycerol concentration.

\section{INTRODUCTION}

In the last decades, much attention has been given to the production of biofuels, in order to reduce the dependence on fossil fuels. Biodiesel is one of the most common biofuels, which may be used directly in internal combustion engines (Rashid et al., 2008). Its production has increased rapidly in the last decade. In Europe, 3,184,000 tons were produced in 2005, 5,713,000 tons in 2007 and $9,570,000$ tons in 2010 (http://www.ebb-eu.org/stats.php). Biodiesel is formed via the transesterification reaction, where glycerol is the main by-product, corresponding to $10 \%$ of the produced mass of biodiesel. The disposal of the huge surplus of glycerol caused a decrease in biodiesel price and a financial crisis in many industries associated with glycerol production (Torrijos et al., 2008).

The conventional use of glycerol is in cosmetic, paint, food, tobacco and pharmaceutical industries. It is also used as a feedstock for the production of various chemicals (Johnson et al., 2007). Thermochemical processes, such as catalytic steam reforming, partial oxidation and pyrolysis, convert glycerol to hydrogen, methane and other derivatives (Fan et al., 2010). Specifically, steam reforming of glycerol leads to the production of $\mathrm{H}_{2}, \mathrm{CH}_{4}, \mathrm{CO}_{2}$ and $\mathrm{CO}$. The relative amounts of these compounds depends on the nature of the catalyst used and the operational conditions such as temperature and pressure (Nichele et al., 2012; Chen and Zhao, 2012). On the other hand, biochemical processes, such as anaerobic digestion and fermentation could potentially transform 
glycerol into methane and hydrogen, respectively. These processes are preferable to their chemical counterparts, as they are more environmentally friendly.

Anaerobic digestion is a well known process, in which a mixed population of microorganisms degrades the organic matter in the absence of oxygen, while forming biogas (a mixture of methane and carbon dioxide). To date, only a few studies have dealt with biogas production from glycerol, and the majority of them have focused on the valorization of crude industrial glycerol (a stream derived from biodiesel production). Yang et al. (2008) have studied the anaerobic digestion of pure glycerol using a fixed - bed reactor, packed with microorganisms immobilized on polyurethaner. The removal of dissolved organic carbon (DOC) was approximately $86.7 \%$, at an organic loading rate of $1 \mathrm{~g}\left(\mathrm{~L}_{\text {reactor }} \mathrm{d}\right)^{-1}$ under thermophilic conditions $\left(55^{\circ} \mathrm{C}\right)$. Siles et al. (2009) investigated anaerobic digestion of glycerol in batch reactors, using two different types of inocula: granular and non-granular sludge. They found that the highest methane yield was obtained using granular sludge and its value was $0.306 \mathrm{~m}^{3}(\mathrm{~kg} \text { glycerol })^{-1}$. Moreover, crude glycerol has been added as a supplement in codigestion with other wastes (such as municipal solid wastes, agro-industrial by-products and cattle slurry) to enhance methane production (Fountoulakis et al., 2010; Robra et al., 2010) using CSTR type reactors.

Several studies have dealt with the biodegradation of glycerol using pure microbial cultures for the production of different metabolites, such as poly 3-hydroxybutyrate (Qatibi et al., 1988, Mothes et al., 2007) or 1-3 propanediol (Asad et al., 2008). Hydrogen may be produced during the fermentation of glycerol, using either pure or mixed microbial cultures. During fermentative hydrogen production, along with hydrogen, other metabolic products are generated, such as fatty acids, ethanol and lactate (Antonopoulou et al., 2007; 2008). The distribution between hydrogen and the various fermentation end-products highly depends on many factors, such as the feedstock, the initial substrate concentration, the initial and final $\mathrm{pH}$ value (Wang and Wan, 2009, Antonopoulou et al., $2010 ; 2011)$. Ito et al. (2005) first studied the possibility of hydrogen and ethanol production from a glycerol-containing waste, using a pure microbial culture of Enterobacter aerogenes HU-101. However, the potential of using pure glycerol, without any other impurities, which possibly affect hydrogen production and the final metabolic products distribution, has not been studied systematically, so far. Only Akutsu et al. (2009) explored the feasibility of hydrogen production of various types of substrates, among them pure glycerol, using different kinds of inocula. From their research studies, a hydrogen yield of $0.0115-0.0381 \mathrm{~L} \mathrm{H}_{2}(\mathrm{~g} \mathrm{COD} \text { glycerol })^{-1}$ was obtained, depending on the inoculum used.

In order to assess the potential of methane and hydrogen production from pure glycerol, without the effect of other compounds, normally contained in crude glycerol, pure glycerol was used in this study, as substrate for hydrogen and methane production. Anaerobic digestion of glycerol was studied using a conventional type stirred tank reactor at various organic loading rates $(0.25,0.375$ and $0.5 \mathrm{~g} \mathrm{COD} \mathrm{L}^{-1} \mathrm{~d}^{-1}$ ) under mesophilic conditions. Hydrogen production was investigated in batch reactors, for various initial glycerol concentrations and initial $\mathrm{pH}$ values.

\section{MATERIALS AND METHODS}

\subsection{Experiments for methane production}

Mesosphilic methanogenic sludge obtained from the Patras (Western Greece) wastewater treatment plant was used as inoculum. The main sludge characteristics were: $\mathrm{pH}=7.46$, total suspended solids $($ TSS $)=23.23 \mathrm{~g} \mathrm{~L}^{-1}$, volatile suspended solids (VSS) $=11.74 \mathrm{~g} \mathrm{~L}^{-1}$, dissolved Chemical Oxygen Demand $(\mathrm{dCOD})=0.345 \mathrm{~g} \mathrm{~L}^{-1}$ and alkalinity $=5.75 \mathrm{~g} \mathrm{CaCO}_{3} \mathrm{~L}^{-1}$.

The reactor used for methane production was a CSTR (continuous stirred tank reactor) type and was operated under mesophilic conditions $\left(35^{\circ} \mathrm{C}\right)$. It was cylindrical in shape (5L, total volume), made of stainless steel and was continuously stirred. During start-up, the reactor was filled with $3 \mathrm{~L}$ of anaerobic sludge and remained for $24 \mathrm{~h}$ in batch mode. In the sequel, the reactor was switched to continuous mode. The feed solution was kept refrigerated at $4^{\circ} \mathrm{C}$. The feeding of the bioreactor was intermittent and was done via a peristaltic pump, which was set to turn on every $8 \mathrm{~h}$, so that the mean hydraulic retention time (HRT) remained at $20 \mathrm{~d}$. The outflow took place by overflow, and this allowed the reactor to maintain a constant volume.

The feeding medium consisted of $1.18 \mathrm{~g} \mathrm{~L}^{-1}\left(\mathrm{NH}_{4}\right)_{2} \mathrm{HPO}_{4}, 5.5 \mathrm{~g} \mathrm{~L}^{-1} \mathrm{NaHCO}_{3}, 10 \mathrm{~mL} \mathrm{~L}^{-1}$ of the trace metal solution (Skiadas and Lyberatos, 1998) and $0.3 \mathrm{~g} \mathrm{~L}^{-1}$ yeast extract, along with glycerol at concentrations of $5,7.5$ and $10 \mathrm{~g} \mathrm{COD} \mathrm{L}^{-1}$, corresponding to organic loading rates (OLR) of 0.25 , 
0.375 and $0.5 \mathrm{~g} \mathrm{COD} \mathrm{L}^{-1} \mathrm{~d}^{-1}$, respectively. The bioreactor was maintained at a constant OLR, until a steady state was reached, whenever possible.

\subsection{Experiments for hydrogen production}

Anaerobic mesophilic methanogenic sludge was used as inoculum for the experiments of hydrogen production. It was boiled at $100^{\circ} \mathrm{C}$ for $15 \mathrm{~min}$ to eliminate methanogenic microorganisms and select for the hydrogen-producing clostridia (Chen and Lin, 2001).

Batch hydrogen experiments were conducted in serum vials of total volume of $160 \mathrm{~mL}$. The vials were seeded with $10 \mathrm{~mL}$ of inoculum and $50 \mathrm{~mL}$ of nutrient medium, which contained $\mathrm{NaH}_{2} \mathrm{PO}_{4}{ }^{*} 2 \mathrm{H}_{2} \mathrm{O} 7.26 \mathrm{~g} \mathrm{~L}^{-1}, \mathrm{Na}_{2} \mathrm{HPO}_{4}{ }^{*} 2 \mathrm{H}_{2} \mathrm{O} 4.16 \mathrm{~g} \mathrm{~L}^{-1}$, yeast extract $0.5 \mathrm{~g} \mathrm{~L}^{-1}$ and $10 \mathrm{~mL} \mathrm{~L}^{-1}$ of trace elements (Skiadas and Lyberatos, 1998). Control experiments, using glucose instead of glycerol, were carried out for checking the methanogenic biomass activity. Blank experiments were also carried out, in order to determine the background gas productivity of the inoculum. The content of the vials was gassed with a mixture of $\mathrm{N}_{2} / \mathrm{CO}_{2}(80 / 20 \%)$, in order to secure anaerobic conditions. Eventually, vials were sealed with butyl rubber stoppers with aluminium crimps and fermentation took place inside an incubator at $35^{\circ} \mathrm{C}$ and constant stirring. Hydrogen production was monitored versus time.

In the first series of experiments, the effect of initial glycerol concentration $(8.3,12.5$ and $25 \mathrm{~g}$ COD glycerol $\mathrm{L}^{-1}$ ) on hydrogen production was investigated. In the sequel, the $\mathrm{pH}$ influence on hydrogen

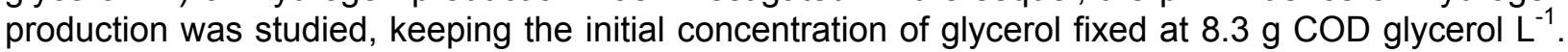
In these experiments, the $\mathrm{pH}$ was adjusted through the addition of $\mathrm{HCl} 1 \mathrm{~N}$ and $\mathrm{NaOH} 1 \mathrm{~N}$ giving initial $\mathrm{pH}$ values of $8,7,6.5,6,5.5,5$ and 4.5 , respectively.

\subsection{Analytical Methods}

Hydrogen and methane were determined in a gas chromatograph (SRI MG\#1, two columns in series: a molecular sieve column, $6 \mathrm{ft}$., O.D. $1 / 8 \mathrm{in}$., I.D. $2.1 \mathrm{~mm}$ and a silica gel column, $6 \mathrm{ft}$., O.D. $1 / 8$ in) equipped with a TCD detector. The column oven temperature was set at $80^{\circ} \mathrm{C}$, the injector valve at $90^{\circ} \mathrm{C}$ and the TCD oven was programmed at $100^{\circ} \mathrm{C}$. Helium and nitrogen was used as carrier gases for methane and hydrogen measurements respectively, at $20 \mathrm{~mL} \mathrm{~min}^{-1}$.

For the quantification of volatile fatty acids (VFAs) and butanol, $1 \mathrm{~mL}$ of sample, acidified with $30 \mu \mathrm{L}$ of $20 \% \mathrm{H}_{2} \mathrm{SO}_{4}$ was injected into a gas chromatograph (VARIAN CP-30), equipped with a flame ionization detector and a capillary column $(30 \mathrm{~m}, 0.53 \mathrm{~mm}$ ID). The oven temperature was raised from 105 to $160^{\circ} \mathrm{C}$, at a rate of $15^{\circ} \mathrm{C} \mathrm{min}^{-1}$, and subsequently, to $235^{\circ} \mathrm{C}$ at a rate of $20^{\circ} \mathrm{C} \mathrm{min}{ }^{-1}$ and was held for $3 \mathrm{~min}$. Helium was used as the carrier gas at $15 \mathrm{~mL} \mathrm{~min}^{-1}$, the injector temperature was set at $175^{\circ} \mathrm{C}$ and the detector at $225^{\circ} \mathrm{C}$.

COD, TSS and VSS measurements were carried out according to Standard Methods (APHA, 1995). 1,3 PDO was measured with high performance liquid chromatography (Dionex Ultimate 3000) equipped with a cation-exchanger column (Shodex PX-87H, $300 \mathrm{~mm} \times 7,8 \mathrm{~mm}$ ) and a RI detector (Shodex). The mobile phase consisted of $\mathrm{H}_{2} \mathrm{SO}_{4} 0.004 \mathrm{~N}$ and its flow was $0.9 \mathrm{~mL} \mathrm{~min}{ }^{-1}$. The temperature of the column was set at $55^{\circ} \mathrm{C}$. Glycerol, ethanol and D/L-Lactic were determined with enzymatic reagent kits (Megazyme K-GCROL, K-ETOH, K-DLATE).

\section{RESULTS AND DISCUSSION}

\subsection{Experiments for methane production}

The values of the main characteristics of the reactor at the different organic loading rates (OLRs) are presented in table 1. Initially, the reactor was operated at an OLR of $0.25 \mathrm{~g} \mathrm{COD} \mathrm{L}^{-1} \mathrm{~d}^{-1}$ and the yields of methane and biogas were $0.21 \pm 0.02$ and $0.36 \pm 0.04 \mathrm{~L}(\mathrm{~g} \mathrm{COD} \text { glycerol added })^{-1}$, respectively. In this phase, the COD concentration was $0.25 \pm 0.02 \mathrm{~g} \mathrm{COD} \mathrm{L}^{-1}$ and the COD removal was $95 \%$. In the sequel, the OLR was doubled to $0.5 \mathrm{~g} \mathrm{COD} \mathrm{L}^{-1} \mathrm{~d}^{-1}$ aiming at investigating the response of the reactor at higher OLRs. This caused an immediate increase in biogas and methane production in response to the OLR increase, but the methane and biogas production decreased gradually, after a few days of reactor operation at this OLR. The decrease in biogas production was accompanied, as anticipated, by a high increase in the concentrations of COD and VFAs. VFAs accumulation caused a pH drop below 6.7, causing inhibition to methanogens and a cessation of methane production. Then, the OLR was reduced to $0.375 \mathrm{~g} \mathrm{COD} \mathrm{L}^{-1} \mathrm{~d}^{-1}$, but the reactor did not 
recover. Thus, the OLR was reset to the initial $0.25 \mathrm{~g} \mathrm{COD} \mathrm{L}^{-1} \mathrm{~d}^{-1}$ and was operated at this OLR from $122 d$ to $500 d$.

The result of the organic loading rate reduction to $0.25 \mathrm{~g} \mathrm{COD} \mathrm{L}^{-1} \mathrm{~d}^{-1}$ was the consumption of the VFAs, so that the reactor stopped to be kinetically limited. At the steady state, the concentrations of the COD and VFAs were $0.29 \pm 0.09$ and $0.26 \pm 0.09 \mathrm{~g} \mathrm{COD} \mathrm{L}^{-1}$ respectively, as presented in table 1. Moreover, the COD removal was $94 \%$ revealing that glycerol was fully converted to methane. At this OLR, the reactor achieved the highest yield of biogas and methane, which were $0.42 \pm 0.05$ and $0.30 \pm 0.04 \mathrm{~L}(\mathrm{~g} \mathrm{COD})^{-1}$, respectively. The $\mathrm{pH}$ value was $7.22 \pm 0.04$, the alkalinity was $3.98 \pm 0.50 \mathrm{~g}$ $\mathrm{CaCO}_{3} \mathrm{~L}^{-1}$ and the concentrations of TSS and VSS were $2.45 \pm 0.26$ and $1.42 \pm 0.17 \mathrm{~g} \mathrm{~L}^{-1}$, respectively. Finally, the OLR was reset to $0.375 \mathrm{~g} \mathrm{COD} \mathrm{L}^{-1} \mathrm{~d}^{-1}$, but the reactor did not withstand this OLR, since the COD and the VFAs started to accumulate and their concentrations were approximately 10 -fold the respective at the OLR of $0.25 \mathrm{~g} \mathrm{COD} \mathrm{L}^{-1} \mathrm{~d}^{-1}$. This means that the reactor started again to be kinetically limited. The overall operation of the reactor showed that it could not withstand organic loading rates above $0.25 \mathrm{~g} \mathrm{COD} \mathrm{L}^{-1} \mathrm{~d}^{-1}$, because of VFAs accumulation and $\mathrm{pH}$ decrease.

Table 1. The mean values of the main variables of the CSTR

\begin{tabular}{|c|c|c|c|c|c|}
\hline \multirow[b]{2}{*}{ Parameters } & \multicolumn{5}{|c|}{ Organic Loading Rates $\left(\mathrm{g}\right.$ COD L $\left.{ }^{-1} \mathrm{~d}^{-1}\right)$} \\
\hline & $\begin{array}{c}0.25 \\
\text { (from } 0 \\
\text { to } 97 d \text { ) } \\
\end{array}$ & $\begin{array}{c}0.5^{*} \\
\text { (from } 98 \\
\text { to } 111 d \text { ) }\end{array}$ & $\begin{array}{c}0.375^{*} \\
\text { (from } 112 \\
\text { to } 121 \mathrm{~d} \text { ) }\end{array}$ & $\begin{array}{c}0.25 \\
\text { (from } 122 \\
\text { to } 500 \mathrm{~d} \text { ) } \\
\end{array}$ & $\begin{array}{c}0.375^{\star} \\
\text { (from } 501 \text { to } \\
574 d \text { ) }\end{array}$ \\
\hline $\begin{array}{l}\text { Biogas } \\
\left(\mathrm{L}(\mathrm{g} \text { COD })^{-1}\right)\end{array}$ & $0.36 \pm 0.04$ & $\#$ & \# & $0.42 \pm 0.05$ & \# \\
\hline $\begin{array}{l}\mathrm{CH}_{4} \\
\left(\mathrm{~L}(\mathrm{~g} \text { COD })^{-1}\right)\end{array}$ & $0.21 \pm 0.02$ & \# & $\#$ & $0.30 \pm 0.04$ & $\#$ \\
\hline $\operatorname{COD}\left(\mathrm{g} \mathrm{L}^{-1}\right)$ & $0.25 \pm 0.02$ & $>3$ & $>3$ & $0.29 \pm 0.09$ & $>3$ \\
\hline $\begin{array}{l}\text { VFAs } \\
\left(g^{-1} \mathrm{COD} \mathrm{L}^{-1}\right)\end{array}$ & $0.25 \pm 0.04$ & $>3$ & $>3$ & $0.26 \pm 0.09$ & $>2$ \\
\hline $\mathrm{pH}$ & $7.01 \pm 0.07$ & $<7.0$ & $<6.8$ & $7.22 \pm 0.04$ & $<6.7$ \\
\hline $\begin{array}{l}\text { Alkalinity } \\
\left(\mathrm{g} \mathrm{CaCO}_{3} \mathrm{~L}^{-1}\right)\end{array}$ & $4.56 \pm 0.31$ & $4.67 \pm 0.19$ & $4.72 \pm 0.30$ & $3.98 \pm 0.50$ & $3.05 \pm 0.34$ \\
\hline $\operatorname{TSS}\left(\mathrm{g} \mathrm{L}^{-1}\right)$ & $2.81 \pm 0.37$ & $3.81 \pm 0.89$ & $4.21 \pm 0.67$ & $2.45 \pm 0.26$ & $1.95 \pm 0.33$ \\
\hline $\operatorname{VSS}\left(\mathrm{g} \mathrm{L}^{-1}\right)$ & $1.56 \pm 0.23$ & $2.08 \pm 0.48$ & $2.42 \pm 0.40$ & $1.42 \pm 0.17$ & $1.31 \pm 0.23$ \\
\hline
\end{tabular}

* These phases do not correspond strictly to a steady state. \# corresponds to dynamic phase

\subsection{Experiments for hydrogen production}

\subsubsection{The effect of initial substrate concentration}

Among the various factors that determine process performance, the substrate concentration is especially important. According to Yu and Fang (2001) the influent organic concentration influences the distribution of metabolic products during fermentation.

In these experiments, hydrogen production was studied at three different initial concentrations of glycerol $\left(8.3,12.5\right.$ and $\left.25 \mathrm{~g} \mathrm{COD} \mathrm{glycerol} \mathrm{L}^{-1}\right)$, at a constant initial $\mathrm{pH}$ of 6.5 . It was observed that although the highest hydrogen evolution was obtained when the initial glycerol concentration was 25 $\mathrm{g} \mathrm{COD} \mathrm{L}^{-1}$ (Figure 1), the highest hydrogen yield was obtained at a glycerol concentration of $8.3 \mathrm{~g}$ $\mathrm{COD} \mathrm{L}^{-1}$. In particular, for this concentration, the yield of produced hydrogen was $26.26 \pm 1.28 \mathrm{~mL} \mathrm{H}_{2}$ $(\mathrm{g} \mathrm{COD} \text { added })^{-1}$. On the other side, the yield decreased to $22.19 \pm 0.74 \mathrm{~mL} \mathrm{H}_{2}(\mathrm{~g} \mathrm{COD} \text { added })^{-1}$ and $16.23 \pm 0.85 \mathrm{~mL} \mathrm{H}_{2}\left(\mathrm{~g} \mathrm{COD}_{\text {added }}\right)^{-1}$ when the concentration increased to 12.5 and $25 \mathrm{~g} \mathrm{COD} \mathrm{L}^{-1}$, respectively.

\subsubsection{The effect of initial $\mathrm{pH}$ value}

In these experiments, the influence of the initial $\mathrm{pH}$ value on hydrogen production from pure glycerol was assessed. The experiments in which the effect of different initial glycerol concentrations on hydrogen production was studied showed that the glycerol influent concentration of $8.3 \mathrm{~g} \mathrm{COD} \mathrm{L}^{-1}$ 
resulted to maximum hydrogen yield. The initial $\mathrm{pH}$ values were $8,7,6.5,6,5.5,5$ and 4.5, respectively. The hydrogen yields obtained for different initial pH values, are presented in Figure 2.

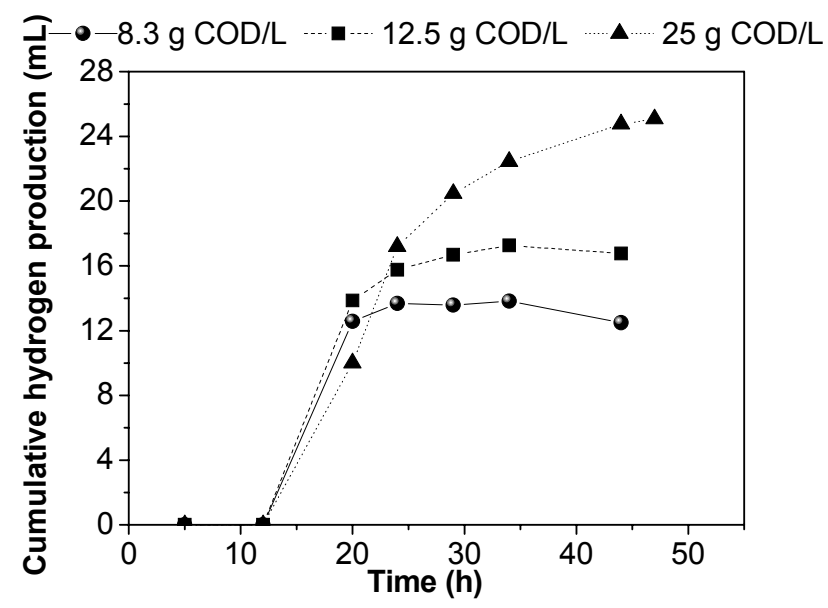

Figure 1. Hydrogen production versus time in different concentrations of glycerol: 8.3, 12.5 and 25 (g COD $L^{-1}$ ), respectively

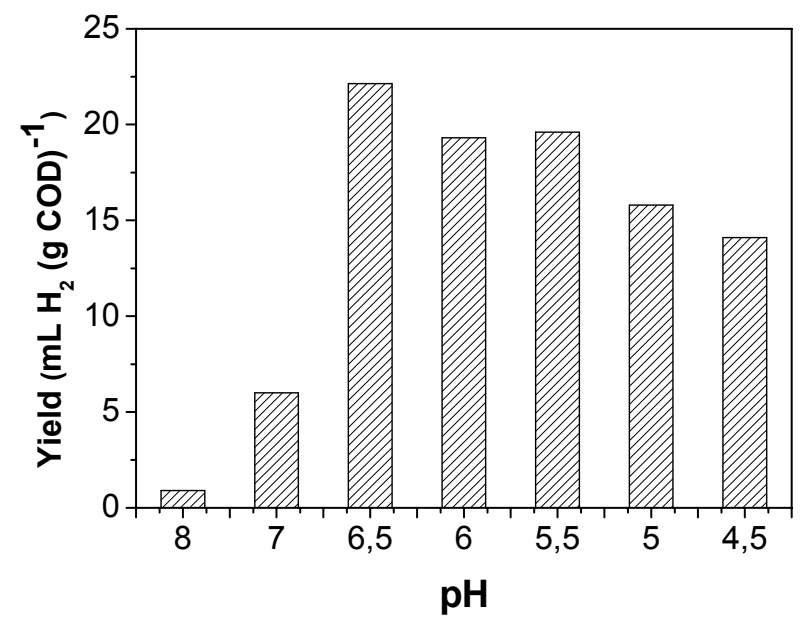

Figure 2. The influence of initial $\mathrm{pH}$ on the hydrogen yield, during glycerol fermentation

The hydrogen yield was too low, when the glycerol fermentation was conducted at alkaline conditions (initial pH value of 8). However, a small decrease in the initial $\mathrm{pH}$ from 8 to 7 resulted in a rapid increase in the hydrogen yield from $0.90 \pm 0.02$ to $6.0 \pm 0.3 \mathrm{~mL} \mathrm{H}_{2}(\mathrm{~g} \mathrm{COD})^{-1}$. An additional reduction of the $\mathrm{pH}$ to 6.5 resulted to an increase in hydrogen yield to $22.14 \pm 0.46 \mathrm{~mL} \mathrm{H}_{2}(\mathrm{~g} \mathrm{COD})^{-1}$. This was the maximum hydrogen yield, since a further decrease in initial $\mathrm{pH}$ resulted in lower yields of hydrogen. Specifically, the initial $\mathrm{pH}$ values of $6,5.5,5$ and 4.5 led to hydrogen yields of $19.3 \pm 1.1$, $19.6 \pm 0.18,15.8 \pm 0.7$ and $14.1 \pm 0.6 \mathrm{~mL} \mathrm{H}_{2}(\mathrm{~g} \mathrm{COD})^{-1}$ respectively. The maximum yield of 0.02214 $\mathrm{L} \mathrm{H}_{2}(\mathrm{~g} \mathrm{COD})^{-1}$ is comparable with the respective obtained by Akutsu et al. (2009) (0.0115-0.0381 L $\mathrm{H}_{2}(\mathrm{~g} \mathrm{COD})^{-1}$ who used different kind of inocula for pure glycerol fermentation. To date, the effect of initial $\mathrm{pH}$ on hydrogen production by mixed microbial cultures, in batch systems, has been investigated for different kind of feedstocks (Fang et al., 2004; Van Ginkel et al., 2005). However, there is a wide range of $\mathrm{pH}$ values, which have been proposed as "optimum" for fermentative hydrogen production. This can be attributed to the differences in inocula, operation modes and the initial $\mathrm{pH}$ range studied (Antonopoulou et al., 2010).

Figure 3 presents the main metabolic products, which were obtained at the end of batch experiments, which exhibited high hydrogen yields (initial $\mathrm{pH}$ values of 4.5-6.5). It is obvious that glycerol was not completely consumed at the $\mathrm{pH}$ range of 4.5-5.5, which in turn implies that, under these conditions, the glycerol fermentation was kinetically limited. However, when the initial $\mathrm{pH}$ was 6.5 (where the maximum hydrogen yield was obtained), glycerol was almost completely consumed. 
1,3 propanediol (PDO) was the main metabolic product at all $\mathrm{pH}$ values, as presented in figure 3 . In addition, acetic acid exhibited high concentration, especially for an initial $\mathrm{pH}$ of 6.5 . At this $\mathrm{pH}$, butyric acid increased, accounting for $6.9 \%$ of the final COD concentration.

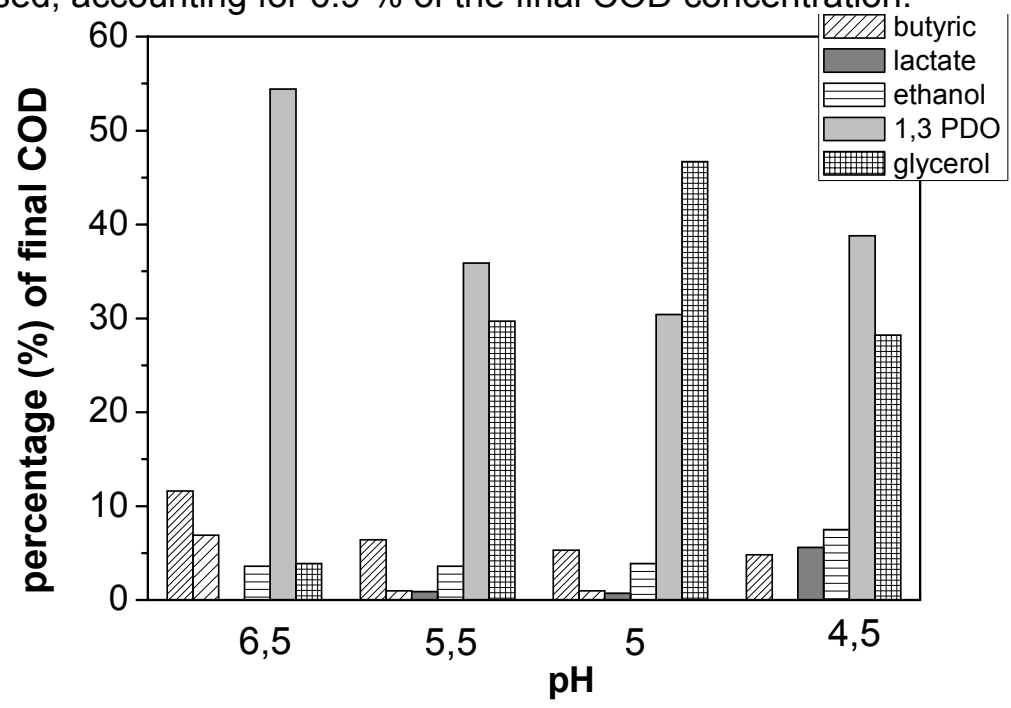

Figure 3. The influence of initial $\mathrm{pH}$ on the metabolic product distribution during glycerol fermentation

The increase in acetic and butyric acid concentrations was accompanied by a simultaneous increase in hydrogen yield, since hydrogen production is related to the production of acetate and butyrate (Antonopoulou et al., 2008). At the $\mathrm{pH}$ value of 6.5 , the dominant metabolic product was 1,3 PDO, which corresponded to $54.4 \%$ of the final COD concentration. Similar results were obtained by Akutsu et al. (2009), who studied hydrogen production from glycerol fermentation under different initial conditions. Formate and butanol were not detected in all experiments, while lactate and ethanol had a low contribution to the measured final COD values, especially at an initial $\mathrm{pH}$ range of 5-6.5 (figure 3). When the initial pH was 4.5, lactate and ethanol increased significantly, implying that the production of reduced end products is associated with low hydrogen yields (Lay, 2000; Antonopoulou et al., 2010). The culture $\mathrm{pH}$ was in the range of 4.5-5.9 for all initial $\mathrm{pH}$ values.

\subsection{Biofuels generation from glycerol}

From the experimental results, it can be concluded that glycerol can be used as a substrate for methane and hydrogen production. The maximum methane yield is $\left.0.30 \pm 0.04 \mathrm{~L}_{(\mathrm{g} \mathrm{COD}}\right)^{-1}$, while the maximum hydrogen yield is $0.02214 \pm 0.00046 \mathrm{~L}(\mathrm{~g} \mathrm{COD})^{-1}$. The energy that could be obtained when $1 \mathrm{~g} \mathrm{COD}$ of glycerol is converted to methane is $10.74 \mathrm{~kJ}$, while the respective energy for hydrogen is $244 \mathrm{~J}$ (assuming that the energy yield from methane is $50.120 \mathrm{~kJ} \mathrm{~kg}^{-1}$ and from hydrogen is $122.000 \mathrm{~kJ} \mathrm{~kg}^{-1}$ ). Taking into account that glycerol is the main bio-product from the biodiesel production process, the energy exploitation of glycerol for biofuels production (which corresponds to $10.98 \mathrm{~kJ}(\mathrm{~g} \mathrm{COD} \text { glycerol })^{-1}$ ) could be a promising alternative process contributing to the biodiesel economy.

In general, biochemical processes such as fermentative hydrogen production or anaerobic digestion, are conducted at low temperatures and pressures, which is desirable from an environmental point of view. The energy demands of these processes are much lower compared to the respective chemical processes, such as steam reforming, glycerol pyrolysis and partial oxidation, which are conducted at high temperatures, consuming huge amounts of power (Holladay et al., 2009; Fernandez et al., 2009). Despite the high energy demands, chemical processes are often more effective in terms of the obtained products rates and yields, than the biochemical processes. For instance, in this study the hydrogen production (expressed in mole/mole of glycerol) was only 0.13 , while hydrogen production from glycerol by reforming in supercritical water $\left(700-800^{\circ} \mathrm{C}\right)$ was found to be $7 \mathrm{~mol}$ of hydrogen/mol of glycerol (Byrd et al., 2008) and hydrogen production by steam reforming of glycerol over $\mathrm{Ni} / \mathrm{CeO}_{2}$ catalysts $\left(400-700^{\circ} \mathrm{C}\right)$ prepared by precipitation deposition method, was found to be $5.6 \mathrm{~mol}$ of hydrogen/mol of glycerol (Pant et al., 2011). In order to decide for the most effective process for glycerol valorization and conversion to hydrogen, it is necessary to take into account both economic (based on energy demands) and technical (based on hydrogen yield) aspects. 


\section{CONCLUSIONS}

In this study, the anaerobic exploitation of glycerol, for methane and hydrogen production, was investigated. Anaerobic digestion, of pure glycerol was conducted in a CSTR operated under mesophilic conditions $\left(35^{\circ} \mathrm{C}\right)$ at various organic loading rates. The overall operation of the reactor showed that it could not withstand organic loading rates above $0.25 \mathrm{~g} \mathrm{COD} \mathrm{L}^{-1} \mathrm{~d}^{-1}$, because of VFAs accumulation and $\mathrm{pH}$ decrease. At this OLR, the maximum methane yield was achieved and it was $0.30 \pm 0.04 \mathrm{~L}(\mathrm{~g} \mathrm{COD})^{-1}$.

Fermentative hydrogen production was carried out in batch mesophilic reactors, where the effect of initial glycerol concentrations and initial $\mathrm{pH}$ value, on hydrogen production were studied. The highest yield was $22.14 \pm 0.46 \mathrm{~mL} \mathrm{H}_{2}\left(\mathrm{~g} \mathrm{COD}_{\text {added }}\right)^{-1}$ at initial $\mathrm{pH}$ of 6.5 and an initial glycerol concentration of $8.3 \mathrm{~g} \mathrm{COD} \mathrm{L}^{-1}$. The main metabolic product was 1.3 propanediol (PDO), while at lower concentrations, butyric acid, acetic acid and ethanol were also generated.

\section{REFERENCES}

Akutsu Y., Lee D.-Y., Li Y.-Y. and Noike T., (2009), Hydrogen production potentials and fermentative characteristics of various substrates with different heat-pretreated natural microflora, International Journal of Hydrogen Energy, 34, 5365-5373.

Antonopoulou G., Gavala H.N., Skiadas I.V. and Lyberatos G., (2010), Influence of pH in fermentative hydrogen production from sweet sorghum extract, International Journal of Hydrogen Energy, 35, 19211928.

Antonopoulou G., Gavala H.N., Skiadas I.V. and Lyberatos G., (2011), Effect of substrate concentration on fermentative hydrogen production from sweet sorghum extract, International Journal of Hydrogen Energy, 36, 4843-4851.

Antonopoulou G., Gavala H.N., Skiadas I.V., Angelopoulos K. and Lyberatos G., (2008), Biofuels generation from sweet sorgum: Fermentative hydrogen production and anaerobic digestion of the remaining biomass, Bioresource Technology, 99, 110-119.

Antonopoulou G., Ntaikou I., Gavala H.N, Skiadas I.V., Angelopoulos K. and Lyberatos G., (2007), Biohydrogen production from sweet sorghum biomass using mixed acidogenic cultures and pure cultures of Ruminococcus albus, Global NEST Journal, 9, 144-151.

APHA, AWWA, WPCF (1995), Standard Methods for the examination of Water and Wastewater, Franson M.A., Ed.; American Public Health Association: Washington, DC.

Asad R., Saman W.R.G., Nomura N., Sato S. and Matsumura M., (2008), Pretreatment and utilization of raw glycerol from sunflower oil biodiesel for growth and 1,3-propanediol production by Clostridium butyricum, Journal of Chemical Technology and Biotechnology, 83, 1072-1080.

Byrd A.J., Pant K.K. and Gupta R.B., (2008), Hydrogen production from glycerol by reforming in supercritical water over $\mathrm{Ru} / \mathrm{Al}_{2} \mathrm{O}_{3}$ catalyst, Fuel, 87, 2956-2960.

Chen C.C. and Lin C.Y., (2001), Start-up of anaerobic hydrogen producing reactors seeded with sewage sludge, Acta Biotechnology, 21, 371-379.

Chen G. and Zhao L., (2012), Preliminary investigation on hydrogen-rich gas production by co-steamreforming of biomass and crude glycerin, International Journal of Hydrogen Energy, 37, 765-773.

European Biodiesel Board, URL: http://www.ebb-eu.org/stats.php (accessed 13/11/2011).

Fan X., Burton R. and Zhou Y., (2010), Glycerol (Byproduct of biodiesel production) as a source for fuels and chemicals - Mini Review, The Open Fuels \& Energy Science Journal, 3, 17-22.

Fang H.H.P., Liu H. and Zhang T., (2004), Bio-hydrogen production from wastewater, Water Science and Technology, 4, 77-85.

Fernandez Y., Arenillas A., Diez M.A., Pis J.J. and Menendez J.A., (2009), Pyrolysis of glycerol over activated carbons for syngas production, Journal of Analyical and Applied Pyrolysis, 84, 145-150.

Fountoulakis M.S. and Manios T., (2010), Enhanced methane and hydrogen production from municipal waste and agro-industrial by-products co-digested with glycerol, Bioresource Technology, 100, 30433047.

Holladay J.D., Hu J, King D.L. and Wang Y., (2009), An overview of hydrogen production technologies, Catalysis Today, 139, 244-260.

Ito T., Nakashimada Y., Senba K., Matsui T. and Nishio N., (2005), Hydrogen and ethanol production from glycerol-containing waste discharged after biodiesel manufacturing process, Journal of Bioscience and Bioengineering, 100, 260-265.

Johnson D.T. and Taconi K.A., (2007), The glycerin glut: options for the value-added conversion of crude glycerol resulting from biodiesel production, Environmental Progress, 26, 338-348. 
Lay J.J., (2000), Modelling and optimization of anaerobic digested sludge converting starch to hydrogen, Biotechnology and Bioengineering, 68, 269-278.

Mothes G., Schnorpfeil C. and Ackermann J.-U., (2007), Production of PHB from crude glycerol. Engineering Life Science, 5, 475-479.

Nichele V., Signoretto M., Menegazzo F., Gallo A., Dal Santo V., Gruciani G. and Cerrato G., (2012), Glycerol steam reforming for hydrogen production: Design of Ni supported catalysts, Applied Catalysis B: Environmental, 111- 112, 225- 232.

Pant K.K., Jain R. and Jain S., (2011), Renewable hydrogen production by steam reforming of glycerol over $\mathrm{Ni} / \mathrm{CeO}_{2}$ catalyst prepared by precipitation deposition method, Korean Journal of Chemical Engineering, 28, 1859-1866.

Qatibi A.I., Bennisse R., Jana M. and Garcia J.-L., (1998), Anaerobic degradation of glycerol by Desulfovibrio fructosovorans and D. carbinolicus and evidence for glycerol-dependent utilization of 1,2propanediol, Current Microbiology, 36, 283-290.

Rashid U. and Anwar F., (2008), Production of biodiesel through optimized alkaline-catalyzed transesterification of rapessed oil, Fuel, 87, 265-273.

Robra S., Cruz R.S., Oliveira A.M., Neto J.A.A. and Santos J.V., (2010), Generation of biogas using crude glycerin from biodiesel production as a supplement to cattle slurry, Biomass and Bioengineering, 34, 1330-1335.

Siles J.A, Santos M., Perez A. and Martin A., (2009), Anaerobic digestion of glycerol derived from biodiesel manufacturing, Bioresource Technology, 100, 5609-5615.

Skiadas I.V. and Lyberatos G., (1998) The Periodic anaerobic baffled reactor, Water Science and Technology, 38, 401-408.

Torrijos M., Thalla A.K., Sousbie P., Bosque F. and Delgenes J.P., (2008), Anaerobic digestion of residues from production and refining of vegetable oils as an alternative to conventional solutions, Water Science and Technology, 58, 1872-1878.

Van Ginkel S.W., Oh S.-E. and Logan B.E., (2005), Biohydrogen gas production from food processing and domestic wastewaters, International Journal of Hydrogen Energy, 30 1535-1542.

Wang J. and Wan W., (2009), Factors influencing fermentative hydrogen production: A review, International Journal of Hydrogen Energy, 34, 799-811.

Yang Y., Tsukahara K. and Sawayama S., (2008), Biodegradation and methane production from glycerolcontaining synthetic wastes with fixed-bed bioreactor under mesophilic and thermophilic anaerobic conditions, Process Biochemistry, 43, 362-367.

Yu H.Q. and Fang H.H.P., (2001), Acidification of mid- and high-strength dairy wastewaters, Water Research, 35, 3697-3705. 